\title{
Correspondence
}

\section{DAY HOSPITALS: STATISTICAL RETURNS}

DEAR SIR,

Recently when analysing data from a census of psychiatric day-patients in South Glamorgan I looked at the official statistics on day-patients and found them rather confusing (DHSS, 1980; Welsh Office, 1981). The main problem is that the numbers of 'places allocated' at day hospitals in general bear little relationship to the numbers 'attending on the last full working day of the year' or to the average daily attendance calculated by dividing the total annual attendance by 250 (assuming a 5-day week and allowing 10 days for holidays). The figures for day places are suspiciously rounded and substantially larger than those for daily attendance, which on the face of it seems to suggest that day hospitals are much underused.

The problem probably lies with the ambiguous notion of a 'day place'. The number of places a day hospital can offer during a week will of course vary according to the frequency with which patients attend, e.g. for a unit offering a maximum of 20 places a day it could vary from 20 , if each patient attended on all 5 days of a working week to 100 , if each attended only once, and the official statistics are probably meant to take account of this. At any rate they refer to places allocated on "the last full working day of the year" (presumably intended to be the same number as on any other day) i.e. to the daily allocation of places. Even so this may not be a very accurate notion in the minds of day hospital staff who have to make the returns. For example, the Tegfan Day Hospital in Cardiff was built to take 200 patients and does take 200-230 a week. However, since the frequency of patients' daily attendance varies so does the daily total vary and the daily average is somewhere around 155; to take a maximum of 200 a day would be well beyond our resources. The statistic we have in fact returned to the Welsh Office for the last working day of 1979 is 200 and in this we are doubtless at fault; in mitigation we would say that only a notional figure could have been given, while admitting that a figure around 150 would have been less erroneous. Judging from published statistics, determining what is meant by 'places allocated' has been a problem to other hospitals as well, and it may be that the average daily attendance would be a better estimate of the daily number of places actually available.

In addition I wonder whether the choice of 'the last full working day of the year' is a good one. Day attendances around Christmas and the New Year are probably not as good as at other times. The figures for most regions for the last day are in fact substantially less than those for the average daily attendance for the whole year.

Whitchurch Hospital,

I. G. PRYCE

Whitchurch,

Cardiff CF4 $7 X B$

\section{References}

Department of Health and Social Security (1980) The Facilities and Services of Mental Illness and Mental Handicap Hospitals in England 1976. Statistical and Research Report Series No 21. London: HMSO.

Welsh OfFICE (1981) Mental Health Statistics for Wales 1979. Welsh Office, Cardiff.

\section{ABNORMAL INVOLUNTARY MOVEMENTS IN THE ELDERLY}

DEAR SIR,

Following an earlier pilot study in elderly patients in a mental handicap hospital (Bicknell and Blowers, 1980), we have recently carried out a prevalence study of abnormal involuntary movements in 12 local authority residential homes for the elderly. A total of 500 subjects, 138 males and 362 females were included in the study. They were rated individually for abnormal movements using a modification of the AIMS examination (NIMH, 1975).

Abnormal involuntary movements were observed in 179 (35.8 per cent) of the 500 subjects. These movements were mostly mild in severity, but orofacial involvement was present in 140 ( 28 per cent).

In the 122 (24.4 per cent) subjects who had received antipsychotic drugs for a minimum period of three months, abnormal involuntary movements were present in 59 (48.4 per cent), and in the 378 (75.6 per 